\title{
Determinants of exclusive breastfeeding practice among mothers of children age less than 6 month in Bahir Dar city administration, Northwest Ethiopia; a community based cross-sectional survey
}

\author{
Abay Sefene", Dereje Birhanu ${ }^{2,}$, Worku Awoke ${ }^{2}$, Tesfaye Taye ${ }^{3}$ \\ ${ }^{1}$ Disaster Risk Management and Food Security Sector expert, Addis Ababa, Ethiopia \\ ${ }^{2}$ Bahir Dar University, College of Medicine and Health Science, Department of Public Health, Bahir Dar, Ethiopia \\ ${ }^{3}$ Bahir Dar University, College of Medicine and Health Science, Department of Pediatrics, Bahir Dar, Ethiopia \\ Email address \\ yomsemayawi@gmail.com (A. Sefene), firedereje@gmail.com (D. Birhanu),workuawo@yahoo.com (W. Awoke) \\ testaye2006@yahoo.com (T. Taye)
}

\section{To cite this article:}

Abay Sefene, Dereje Birhanu, Worku Awoke, Tesfaye Taye. Determinants of Exclusive Breastfeeding Practice among Mothers of Children Age Less Than 6 Month in Bahir Dar City Administration, Northwest Ethiopia; A Community Based Cross-Sectional Survey. Science Journal of Clinical Medicine. Vol. 2, No. 6, 2013, pp. 153-159. doi: 10.11648/j.sjcm.20130206.12

\begin{abstract}
Background- Exclusive breastfeeding is the optimal feeding practice to achieve infants' growth and development. Most mothers breastfeed their children but malnutrition is still prevalent in Ethiopia. Factors affecting exclusive breastfeeding practice are less known in the study area. Therefore the study aimed to assess its determinants among mother of children age less than 6 months in Bahir Dar city administration, Ethiopia. Method: Community based cross sectional survey was conducted from Jan to Feb 2013. In Bahir Dar city administration there were a total 20 (12 Urban \& 8 Rural) Kebles, of which 6 (4 Urban \& 2 Rural) were selected randomly using lottery method. The registration of mothers who had a child age less than 6 months by the local HEW was used as a sampling frame. Data was collected using interviewer administered questionnaire and was entered and analyzed using SPSS version 16. Logistic regression was used to identify determinants. P value $<0.05$ was considered statistically significant. Results: A total of 159 mothers were interviewed (93.5\% response rate). Respondent's mean age was $27.2 \pm 4.6$ years, $2 / 3^{\text {rd }}$ of respondents were housewives by occupation, and more than $90 \%$ of participants were urban residents and were married. Prevalence of exclusive breastfeeding was $49.1 \%$. Mother education level $(A O R=2.99)$, child sex $(A O R=2.22)$, Parity $(A O R=2.46)$, family size $(\mathrm{AOR}=2.92)$, and time of postnatal care $(\mathrm{AOR}=3.44)$ were independent predictors of exclusive breastfeeding practice in the study area. Conclusion \& recommendation: Practice of exclusive breastfeeding was below the WHO recommendation and the target of the fifth Ethiopian Health Sector Development program. Mother education, child sex, parity, family size, and time of postnatal care were the independent predictors of exclusive breast feeding practice. The city administration should work on promoting exclusive breastfeeding practice giving special emphasis to educated mothers. The government should also consider revising the legislation of the two month postpartum maternity leave.
\end{abstract}

Keywords: Exclusive Breastfeeding, Under Six Month, Bahir Dar, Ethiopia

\section{Introduction}

Malnutrition has been responsible directly or indirectly for $60 \%$ of the 10.9 million annual deaths among children under five years of age. Infant and young child feeding practices affect the nutritional status of children under 2 years of age where about $40 \%$ of these deaths are associated with inappropriate feeding practices $[1,2]$.
According to the WHO recommendation, infants should be exclusively breastfed for the first six months and up to two years or beyond. Despite appropriate feeding practice is the most cost effective intervention to reduce child morbidity and mortality, only $38 \%$ of children less than 6 months of age are exclusively breastfed in the developing countries [3, 4].

Even though breastfeeding is a universally accepted and praised behavior in the Ethiopian culture in general and in 
Amhara region in particular, only half (52\%) of mothers practiced exclusive breastfeeding. Malnutrition in Ethiopia is the underlying cause for $57 \%$ of child deaths and the prevalence of stunting $(43 \%)$ and wasting $(12 \%)$ is much higher among Ethiopian under 3 years children $[5,6]$.

Despite studies were conducted in different parts of the country to assess the magnitude and determinants of exclusive breast feeding, the determinant factors for the practice of EBF were not known in the study area, hence the objective of the study was to identify the determinants among mothers of children age less than 6 months in Bahir Dar city administration, Northwest Ethiopia.

\section{Methods}

\subsection{Study Design and Period}

The study was a community based cross sectional survey and was conducted from Jan 2013 to Feb 2013.

\subsection{Study Area and Setting}

The study was conducted in Bahir Dar city administration of Amhara Region, located $564 \mathrm{~km}$ Northwest of Addis Ababa (capital city of Ethiopia). Bahir Dar city administration has a total of 20 Kebeles (12 urban and 8 rural). The total population of the administration in the year of 2011/2012 was 276, 450, of which 231,376 were Urban residents. The proportion of female residents was 141,627. A total of 37,321 under five children were living in the city administration, of which, 12,717 were less than 6 months of age. In the city administration, there were 1 referral hospital, 11 health centers and 10 health posts owned by government, and 2 general hospitals, 44 clinics owned by private organizations [7].

\subsection{Population}

Source populations: All mothers who had a child age less than 6 months and living in the city administration in the previous 6 months prior to the survey.

Study Populations: Mothers who had a child age less than 6 month in the randomly selected Kebele.

Study Unit: Mother who has a child age less than 6 months

\section{Inclusion/exclusion criteria:}

Mothers who had a child age less than 6 month and living in the study area for more than 6 months were included. Those who were not biological care giver or mothers who were unable to communicate due to serious illness at the time of data collection were excluded.

\subsection{Sample Size Determination and Sampling Procedure Sample Size Determination}

The sample size was calculated using single population proportion formula by considering the following assumptions: a $95 \%$ confidence level, $5 \%$ margin of error, $12 \%$ proportion of exclusive breastfeeding practice [8]

$\mathrm{n}=(\mathrm{Z} \alpha / 2)^{2} \mathrm{p}(1-\mathrm{p}) / \mathrm{d}^{2}=(1.96)^{2}(0.12)(0.88) /(0.05)$, therefore the sample size was 162 , Where $n$ - required sample size, Z- critical value for normal distribution at $95 \%$ confidence level (1.96), P- proportion of exclusive breastfeeding practice $(12 \%), \mathrm{d}=0.05$ (5\% margin of error); and adding $5 \%$ non-response rate (8), total sample size required was 170 .

\subsubsection{Sampling Procedures}

In Bahir Dar city administration, there were 20 Kebeles of which 12 were Urban and 8 Rural. From these 20 Kebeles, 6 (4 Urban and 2 Rural) kebeles were selected by simple random sampling using lottery method. On average the number of households in each Kebele and the number of people in each household was 1000 and 5 respectively making the total population at each Kebele about 5000. The number of study participants was allocated proportionally to each Kebele based on number of households in each kebele. The registration of mothers who had a child age less than 6 months by the local HEW was used as a sampling frame. Since six kebeles were selected to get 170 children age less than 6 month, about 28-29 children were selected at each Kebele and to get such children, four to six Gotes/Villages who had high dense households were identified jointly with HEW and mothers who had a child age less than 6 months were included in the study. We walk along the Gotes/Villages until the required sample was completed.

If more than one mother who had a child age less than 6 months was found in the same house, then the mother with the youngest child were selected. Lottery method was used if mothers had a child of the same age. If the eligible mother was absent from the house at the time of data collection, then revisit was done and if they were absent at second visit they were considered as non respondent.

\subsubsection{Variables of the Study}

The dependent variable was practice of exclusive breastfeeding and the independent variables were Sociodemographic/economic variables such as age of mother, marital status, residence, occupation, maternal education, ethnicity, religion, monthly income, husband education; and Health service related factors such as ANC attendance, staff advice on child feeding during ANC, PNC service use,...

\subsubsection{Definitions of terms}

Exclusive breastfeeding Practiced: A mother who feed only breast milk, and no other liquids or solids with the exception of oral rehydration solution, supplements or medicines to the child age less than 6 month since birth.

\subsubsection{Data Collection Tools and Procedures}

Semi structured interviewer administered questionnaire was developed to collect necessary information and it was adapted from the Ethiopian Health and Demographic Survey, and from the WHO infants and young child feeding guide line $[6,9]$. The questionnaire was first developed in English and was translated in to the local language Amharic. Four 
data collectors and one supervisor were recruited and trained for two days. Age of the child was calculated from the date of birth to the date of the survey. For those with written evidence, date of birth was obtained from child health cards and if they don't have written documents, age was established relying on the date given by the mother.

\subsubsection{Data Quality Control Issues}

Questionnaire was prepared in English and was translated in to the local language Amharic. Pre-testing of the questionnaire was made in non selected kebele and correction was made accordingly. Training was given to the data collectors and supervisor. Close supervision of the data collection was carried by the supervisor and investigators.

\subsubsection{Ethical Considerations}

The study was conducted after getting ethical clearance from Bahir Dar University, College of Medicine and Health Sciences ethical review board. Supportive letter was obtained from Amhara Regional Health Bureau and was given to Bahir Dar city administration health office and to the respective Kebeles. Informed consent was obtained from each study participant after the objective of the study was explained. Respondents were also told the right not to respond to the questions they don't want to respond or to terminate the interview at any time.

\subsection{Data Management and Analysis}

The questionnaire was checked manually for completeness and consistencies, and was then coded, entered, and analyzed using SPSS window version 16. Descriptive statistics was computed to determine prevalence of exclusive breastfeeding practice. To identify factors associated with exclusive breastfeeding practice, binary logistic regression analysis was carried at two levels, first bivariate logistic regression was performed to each independent variable with the outcome variable and variables with a $p$ value $<0.2$ were included in the final model (multivariate analysis). Strength of association was measured using odds ratio, and $95 \%$ confidence intervals. Statistical significance was declared at $\mathrm{P}$ value $<0.05$. The findings were presented in text and tables

\section{Result}

A total of 159 mothers of children age less than 6 month were interviewed making the response rate $93.5 \%$. The mean age of the respondents was $27.2 \pm 4.6$ years. More than two third $(73.2 \%)$ of mothers were in the age range of $20-29$ years. Of the total participants, $118(74.2 \%)$ were Orthodox Christian religion followers, and $90 \%$ were urban residents. Almost all (97.5\%) were Amhara ethnic groups, 39 (24.5\%) of mothers were not able to read and write, and more than $2 / 3^{\text {rd }}$ were housewives. Of the total participants, $46 \%$ earns an average family monthly income of less than 1000.00 ETB (53.00 US Dollar). Latrine and pipe water were available in $92.5 \%$, and $86 \%$ of participants respectively [Table 1].
Table 1: Socio demographic/economic characteristics of study participants $(n=159)$ in Bahir Dar city administration, Northwest Ethiopia, Jan - Feb 2013.

\begin{tabular}{|c|c|c|}
\hline Variables & Frequency & percent \\
\hline \multicolumn{3}{|l|}{ Age of the mother } \\
\hline $15-19$ & 04 & 6.5 \\
\hline $20-29$ & 106 & 73.2 \\
\hline $30+$ & 49 & 18.9 \\
\hline \multicolumn{3}{|l|}{ Residence } \\
\hline Urban & 143 & 89.9 \\
\hline Rural & 16 & 10.1 \\
\hline \multicolumn{3}{|c|}{ Current marital status of the mother } \\
\hline Married & 150 & 94.3 \\
\hline Not Married & 09 & 5.7 \\
\hline \multicolumn{3}{|l|}{ Religion of the mother } \\
\hline Orthodox Christian & 118 & 74.2 \\
\hline Muslim & 35 & 22.0 \\
\hline Protestant & 06 & 3.8 \\
\hline \multicolumn{3}{|l|}{ Ethnicity } \\
\hline Amhara & 155 & 97.5 \\
\hline Others* & 04 & 2.5 \\
\hline \multicolumn{3}{|l|}{ Education level of the mother } \\
\hline Unable to read \& write & 39 & 24.5 \\
\hline Primary school & 40 & 25.2 \\
\hline High school/preparatory/ & 45 & 28.3 \\
\hline Diploma and above & 35 & 22.0 \\
\hline \multicolumn{3}{|l|}{ Occupation of the mother } \\
\hline House wife & 113 & 71.1 \\
\hline Government employee & 22 & 13.8 \\
\hline Private employee & 24 & 15.0 \\
\hline \multicolumn{3}{|c|}{ Educational status of the husband } \\
\hline Unable to read and write & 26 & 16.3 \\
\hline Primary school & 35 & 22.0 \\
\hline High school/ preparatory & 40 & 25.2 \\
\hline Diploma and above & 58 & 36.5 \\
\hline \multicolumn{3}{|l|}{ Parity } \\
\hline Primipara & 76 & 47.8 \\
\hline Multipara & 80 & 50.3 \\
\hline Grand Multipara & 03 & 1.9 \\
\hline \multicolumn{3}{|c|}{ Average monthly family income } \\
\hline$\leq 1000.00 \mathrm{ETB}$ & 73 & 45.9 \\
\hline$>1000.00 \mathrm{ETB}$ & 86 & 54.1 \\
\hline \multicolumn{3}{|c|}{ Number of family members in the $\mathbf{H H}$} \\
\hline$<=4$ & 127 & 79.9 \\
\hline$>4$ & 32 & 20.1 \\
\hline \multicolumn{3}{|l|}{ Availability of latrine } \\
\hline Yes & 147 & 92.5 \\
\hline No & 12 & 7.5 \\
\hline \multicolumn{3}{|l|}{ Type of latrine available } \\
\hline Pit latrine & 99 & 67.3 \\
\hline Flush latrine & 48 & 32.7 \\
\hline \multicolumn{3}{|l|}{ Source of drinking water } \\
\hline Pipe & 137 & 86.2 \\
\hline Spring & 04 & 2.5 \\
\hline Well/river & 18 & 1.3 \\
\hline
\end{tabular}

*Oromo, Tigrie 


\section{Maternal and Child Health Service and other Related Characteristics}

Study subjects were asked whether they were attended ANC or not during their current pregnancy and $150(94.3 \%)$ mothers reported that they received ANC service to the current child and more than $80 \%$ of respondents reported that they were told how long they should breastfeed the child. Nearly two third of mothers reported that they breastfeed their children 8 or more times in the previous 24 hours. Regarding to the sex of the child, fifty two percent were males. Practice of exclusive breastfeeding was reported in $49.1 \%$ of mothers. Among mothers who didn't exclusively breastfeed their children, the main reason reported was the perception that breast milk alone was insufficient (Table 2).

Table 2: Maternal \& child health/child feeding \& related characteristics of study participants $(n=159)$ in Bahir city Dar administration, Northwest Ethiopia, Jan-Feb 2013

\begin{tabular}{|c|c|c|}
\hline Variable/Response & Frequency & percent \\
\hline \multicolumn{3}{|l|}{ Antenatal care attendance } \\
\hline Yes & 150 & 94.3 \\
\hline No & 09 & 5.7 \\
\hline \multicolumn{3}{|l|}{ Number of ANC visits } \\
\hline Once & 16 & 10.7 \\
\hline Two to three times & 95 & 63.3 \\
\hline Four times or more & 39 & 26 \\
\hline \multicolumn{3}{|l|}{ Time of PNC follow up } \\
\hline At 6 week & 97 & 61.0 \\
\hline At 6 , and at 10 weeks & 36 & 22.6 \\
\hline At $6,10, \& 14$ weeks or more & 26 & 16.4 \\
\hline \multicolumn{3}{|l|}{ Sex of the child } \\
\hline Male & 83 & 52.2 \\
\hline Female & 76 & 47.8 \\
\hline \multicolumn{3}{|l|}{ Mothers on EBF } \\
\hline Yes & 78 & 49.1 \\
\hline No & 81 & 50.9 \\
\hline \multicolumn{3}{|c|}{ Child feeding education given during pregnancy } \\
\hline Yes & 129 & 81.1 \\
\hline No & 30 & 18.9 \\
\hline \multicolumn{3}{|l|}{ BF frequency in previous $24 \mathrm{hrs}$} \\
\hline$\leq 8$ & 61 & 38.4 \\
\hline$>8$ & 98 & 61.6 \\
\hline \multicolumn{3}{|l|}{ Main reason for not $\mathrm{EBF}(\mathrm{n}=72)$} \\
\hline Breast milk alone was insufficient & 70 & 97.2 \\
\hline Mother left home for work & 02 & 2.8 \\
\hline
\end{tabular}

\section{Determinants of EBF Practice}

Exclusive breastfeeding was practiced in half of the study participants. With regard to the determinants of exclusive breastfeeding practice, each variable were assessed independently whether they were predictors of the practice of EBF or not. Predictor variables identified in the bivariate analysis were residence $(\mathrm{COR}=3.50,95 \% \mathrm{CL}(1.08-11.37))$, maternal education level ( $\mathrm{COR}=2.45,95 \% \mathrm{CL}(1.30-4.64))$, and number of PNC visits $(\mathrm{COR}=2.50 \quad(1.02-6.15)$ ). Variables such as husband education, number of ANC visit, \& family size were marginally significant but other variables included in the model were not significantly associated to the practice of EBF. Variables were included in the final multivariate logistic regression model to see their predictive effect on the practice of exclusive breastfeeding. Maternal education level and time of PNC attendance remained determinants of EBF practice in the multivariate model but residence which was significantly associated to the practice of EBF and Husband education and Number of ANC visits which were marginally associated in the bivariate model had lost their significance in the final model. At the same time child sex, parity, and family size which were not significantly associated to exclusive breastfeeding practice in the bivariate model, were significantly associated to the outcome variable in the final model. With regard to their predictive effect, mothers who were unable to read and write or completed primary school were 3 times more likely to exclusively breastfeed their child than those mothers who completed secondary school or more; $\mathrm{AOR}=2.99,95 \% \mathrm{CL}$ (1.47-6.07). Mothers who lived in a family member of five or more were about three times more likely to EBF their children than those who live in a family member of four or less; $\mathrm{AOR}=2.92,95 \% \mathrm{CL}$ (1.11-7.72). With regard to the sex of the child, those mothers whose child was male were 2 times more likely to practice exclusive breastfeeding than those mothers whose child were female; $\mathrm{AOR}=2.22,95 \%$ CL (1.04- 4.73). Primipara mothers were more than 2 times to practice $\mathrm{EBF}$ than those mothers who were Multipara; $\mathrm{AOR}=2.46,95 \% \mathrm{CL}(1.12-5.40)$ and those mothers who attend postnatal care three times or more were 3 times more likely to practice exclusive breastfeeding than those who attend twice or less; AOR $=3.44,95 \%$ CL (1.30- 9.08) (Table $3)$.

Table 3: Determinants of EBF practice among mothers of children age less than 6 months using bivariate and multivariate logistic regression analysis model, Bahir Dar adminastration, Northwest Ethiopia, Jan - Feb 2013.

\begin{tabular}{|c|c|c|c|c|c|c|}
\hline \multirow{2}{*}{ Variable } & \multicolumn{2}{|c|}{ Practiced EBF } & \multirow{2}{*}{\multicolumn{2}{|c|}{ COR $(95 \%$ CL) \& P value }} & \multirow{2}{*}{\multicolumn{2}{|c|}{ AOR $(95 \%$ CL) \& P. value }} \\
\hline & No & Yes & & & & \\
\hline$<=24$ Years & $25(58.1)$ & $18(41.9)$ & $1.49(0.73-3.02)$ & 0.27 & $1.31(0.58-2.99)$ & 0.52 \\
\hline$>24$ years & $56(46.5)$ & $60(51.7)$ & 1.00 & & 1.00 & \\
\hline \multicolumn{7}{|l|}{ Residence } \\
\hline Urban & $77(53.8)$ & $66(46.2)$ & $3.50(1.08-11.37)$ & 0.04 & $2.26(0.61-8.37)$ & 0.22 \\
\hline
\end{tabular}




\begin{tabular}{|c|c|c|c|c|c|c|}
\hline \multirow{2}{*}{ Variable } & \multicolumn{2}{|c|}{ Practiced EBF } & \multirow{2}{*}{\multicolumn{2}{|c|}{ COR $(95 \%$ CL) \& P value }} & \multirow{2}{*}{\multicolumn{2}{|c|}{ AOR $(95 \%$ CL) \& P. value }} \\
\hline & No & Yes & & & & \\
\hline Rural & $4(25)$ & $12(75)$ & 1.00 & & 1.00 & \\
\hline \multicolumn{7}{|l|}{ Mother education } \\
\hline Unable to read \& write/ primary & $49(62)$ & $30(38)$ & $2.45(1.30-4.64)$ & 0.01 & $2.99(1.47-6.07)$ & 0.002 \\
\hline Secondary school \& higher & $32(40)$ & $48(60)$ & 1.00 & & 1.00 & \\
\hline \multicolumn{7}{|l|}{ Husband education } \\
\hline Unable to read \& write/primary & $37(60.7)$ & $24(39.3)$ & $1.89(0.99-3.62)$ & 0.05 & $1.20(0.41-3.51)$ & 0.74 \\
\hline Secondary school \& higher & $44(44.9)$ & $54(55.1)$ & 1.00 & & 1.00 & \\
\hline \multicolumn{7}{|l|}{ Mother occupation } \\
\hline Housewife & $62(54.9)$ & $51(45.1)$ & $1.73(0.86-3.46)$ & 0.12 & $1.19(0.51-2.75)$ & 0.69 \\
\hline Employed & $19(41.3)$ & $27(58.7)$ & 1.00 & & 1.00 & \\
\hline \multicolumn{7}{|l|}{ Average monthly family income } \\
\hline$<=1000.00$ ЕTВ & $41(56.2)$ & $32(43.8)$ & $1.47(0.79-2.76)$ & 0.23 & $1.88(0.79-4.48)$ & 0.16 \\
\hline$>1000.00$ ЕTB & $40(46.5)$ & $46(53.5)$ & 1.00 & & 1.00 & \\
\hline \multicolumn{7}{|l|}{ Number of $\mathbf{H H}$ members } \\
\hline$<=4$ & $60(47.2)$ & $67(52.8)$ & 1.00 & & 1.00 & \\
\hline$>4$ & $21(65.6)$ & $11(34.4)$ & $2.13(0.95-4.78)$ & 0.07 & $2.92(1.11-7.72)$ & 0.03 \\
\hline \multicolumn{7}{|l|}{ Number of ANC follow up } \\
\hline $1-3$ & $62(54.9)$ & $51(45.1)$ & $1.95(0.93-4.11)$ & 0.08 & $1.92(0.84-4.41)$ & 0.12 \\
\hline $4+$ & $19(41.3)$ & $27(58.7)$ & 1.00 & & 1.00 & \\
\hline \multicolumn{7}{|l|}{ Sex of the child } \\
\hline Male & $47(56.6)$ & $36(43.4)$ & $1.61(0.86-3.02)$ & 1.14 & $2.22(1.04-4.73)$ & 0.04 \\
\hline Female & $34(44.7)$ & $42(55.3)$ & 1.00 & & 1.00 & \\
\hline \multicolumn{7}{|l|}{ Parity } \\
\hline Primipara & $42(55.3)$ & $34(44.7)$ & $1.39(0.75-2.60)$ & 0.29 & $2.46(1.12-5.40)$ & 0.03 \\
\hline Multipara & $39(47)$ & $44(53)$ & 1.00 & & 1.00 & \\
\hline \multicolumn{7}{|l|}{ Mothers who attend PNC } \\
\hline At 6 , and 10 Weeks & $63(47.4)$ & $70(52.6)$ & 1.00 & & 1.00 & \\
\hline At $6,10, \& 14$ Weeks or more & $18(69.2)$ & $8(30.8)$ & $2.50(1.02-6.15)$ & 0.04 & $3.44(1.30-9.08)$ & 0.013 \\
\hline
\end{tabular}

\section{Discussion}

Breastfeeding is unequalled way of providing ideal food for the healthy growth and development of infants. As a global public health recommendation, infants should be EBF for the first 6 months because breast milk is uncontaminated and contains all the nutrients and antibodies that are very important to prevent disease [2].

\subsection{Prevalence of $E B F$}

In this study $49.1 \%$ of mothers reported that they were exclusively breastfeed their current child. The finding of the study was comparable to the 2011 Ethiopian DHS report (52\%), the 2005 Ethiopian DHS report (49\%), a study done in Harar Ethiopia (51.9\%), Tanzanian 2010 national DHS report $(49.9 \%)$, and a study done in the district of peninsular Malaysia (43.1\%) [6, 10-13]. But the finding was lower than studies done in the Sri Lanka national DHS report (60.6\%), Dinajpur district of Bangladesh (61.3\%), in Legon district of Ghana (66\%), in Dodoma municipality of Tanzania, in the rural district of Hoima of western Uganda (57\%), and in Goba district of Ethiopia (73.5\%) [14-19]

\subsection{Determinants of EBF}

This study was aimed to identify determinants of exclusive breastfeeding practice among mothers of children age less than 6 months in Bahir Dar city administration. Education is an important factor influencing individual's attitude and opportunities in life. Although educational attainment in Ethiopia is low among both men and women, women are much more disadvantaged than men. In this study about $50 \%$ of mothers were unable to read and write or in primary school. The finding was comparable to the Ethiopian national education prevalence (51\%) but it was much better as compared to the prevalence report of Amhara region where $63.6 \%$ of adults were unable to read and write [6].

In the multivariate logistic regression model, maternal education was the independent determinant factor to the practice of EBF where mothers who were unable to read and write or in primary school were 3 times more likely to practice EBF than those who completed secondary school or higher. This might be explained by the fact that women who 
were better educated could have a better opportunity for employment that could lead them to be out of house the whole day. In Ethiopia the maternity leave given during the postpartum period is only 2 month therefore this could also affect educated people not to exclusively breastfeed for the first 6 month. At the same time, women may be influenced by media advertising on milk substitutes which will further compromise the practice of EBF. The finding was in agreement to studies done in Saudi Arabia, Ethiopia, Sweden, and Vietnam, [8, 12, 20-21,], but the finding is not consistent with other studies such as in Colombo district of Sir Lanka, Canada national survey report, in the Thane district of India, and a study done in Singapore [22-25].

Feeding practices affect the child's nutritional status, which in turn risk the child to death. In this study mothers who had male children were two times more likely to exclusively breastfeed than those mothers who had female child. This might be due to cultural bias on the sex of the individual where in Ethiopian context more priority or respect is usually given to males than females. The finding was in agreement to studies done in Uganda, Egypt, and India [18, 24, 26-27]. But not in agreement to studies done in Singapore, and Nigeria $[25,28]$.

A large proportion of maternal and neonatal deaths occur during the first 48 hours after delivery, and these two days following delivery are critical for monitoring complications arising from the delivery and also to provide the mother with important information on how to care for herself and to her child. In this study $93.7 \%$ of mothers reported that they attend postnatal service and the proportion of mothers who attend postnatal care at 6 weeks, at 6 and at 10 weeks, and at 6,10 , and14 weeks or more were $61 \%, 22.6 \%$ and $16.4 \%$ respectively. Mothers who attend $\mathrm{PNC}$ at 6,10 , and 14 weeks or more were 3 times more likely to practice exclusive breastfeeding than those who attend at 6 weeks only or at 6 and at 10 weeks only. This might be due to the fact that mothers who attend PNC frequently could be more counseled by health care workers to breastfeed their children exclusively. The finding is supported by the 2011 Ethiopian DHS report where the great majority (92\%) of women didn't receive postnatal checkup and only 52\% did EBF, and also a study done in Sri Lanka indicated that those mothers who didn't attend PNC were less likely to exclusively breastfeed their children than those who attend postnatal service $[6,14]$

The number of pregnancy could affect the child feeding practice. In this study mothers who were primipara were two times more likely to exclusively breastfeed than Multipara mothers. This could be because of the fact that primipara mothers might be young people who could have better access to media and be more knowledgeable on advantage of exclusive breast feeding. The finding was in agreement to a study done in peninsular Malaysia [13] but was not consistent to studies done in Saudi Arabia, Canada, West India, and in the Thane district of India where multiparous mother were more likely to exclusively breastfeed than primipara mothers $[8,23,24,27]$.
Regarding to family size those mothers who had more families (four or more) were three times more likely to exclusively breastfeed than those who lived in a family size of three or less. This might be because those who had more family member could have better educated people that can convince or educate the mother to feed the baby exclusively.

\section{Limitation of the Study}

Since mothers were asked their 24 hour exclusive breastfeeding practice, some infants who were given other liquids regularly may not have received such fluids/foods in the last $24 \mathrm{hrs}$ before the survey which might overestimate the proportion of exclusive breastfeeding practice. Psychosocial variable which could address cultural/traditional practices were not included in the survey questionnaire.

\section{Conclusion and Recommendation}

Prevalence of EBF was much lower than the WHO recommendation, and Ethiopian national HSDP target. Mother education, child sex, parity, family size and time of PNC visit were the predictors for exclusive breastfeeding practice. Despite the majorities were urban residents, sex bias is still the major problem.

The administration should work on promoting behavior change communication on exclusive breastfeeding practice giving special emphasis to educated mothers. The government should also consider revising the legislation of the two month postpartum maternity leave. The administration should also address the problem of sex bias.

\section{Acronyms}

ANC - Antenatal Care, AOR- Adjusted Odds Ratio, COR- Crude Odds ratio, DHS- Demographic Health Survey, EBF- Exclusive Breastfeeding, ETB- Ethiopian Birr, HEW-Health extension Workers, HH- Household, HSDPHealth Sector Development Program, PNC- Postnatal Care, UNICEF-United Nations Children's Fund, WHO- World Health Organization

\section{Authors' Contributions}

All the authors designed the study, contributed on the data collection, entry and analysis. AS and DB drafted the manuscript. All the authors revised and approved the final manuscript

\section{Acknowledgement}

We would like to express our thanks to Amhara regional Finance and economic development Bureau and Bahir Dar city Administration health office for the provision of necessary documents. We also thank data collectors, supervisors and study participants. Authors declare no competing of interest. 


\section{References}

[1] CARE USA. Infant and young child feeding practices: Collecting and Using Data: A Step-by-Step Guide. 2010

[2] WHO. Global strategy for infant and young child feeding. Geneva, 2003

[3] WHO. Fifty-fifth world health assembly: Infant and young child nutrition: Global strategy on infant and young child feeding, Report by the Secretariat. April 2002

[4] UNICEF. Infant and Young Child Feeding, 2008. http :// www. unicef. org/nutrition /index _ breastfeeding. html. Accessed in October 21, 2012

[5] Mary Arimond and Marie T. Ruel. Summary indicators for infant \& Child Feeding Practices: An Example from the Ethiopia Demographic and Health Survey 2000. Food and Nutrition Technical Assistance Project, August 2002

[6] Central Statistical Agency. Ethiopia Demographic and Health Survey 2011: A.A, Ethiopia: ICF International, Calverton, Maryland, USA; March 2012.

[7] Ethiopia Federal Bureau of Finance and Economic development, population projection report, 2011.

[8] Tarek Amin, Hatem Hablas, and Ahmed Al Abd Al Qader. Determinants of Initiation and Exclusivity of Breastfeeding in Al Hassa, Saudi Arabia. Breastfeeding medicine. 2011, Vol. 6, No. 2. DOI: $10.1089 / \mathrm{bfm} .2010 .0018$

[9] WHO. Indicators for assessing infant \& young child feeding practice: Part 2, Measurement ,2010

[10] Kibebew A. Infant and Young Child Feeding Practices among Mothers Living in Harar, Ethiopia. Harar Bulletin of Health Sciences; January 2012,Extracts Number 4,

[11] Victor R, Baines SK, Agho KE, et al. Determinants of breastfeeding indicators among children less than 24 months of age in Tanzania: Tanzania Demographic and Health Survey. BMJ Open 2013; 3: e001529. doi:10.1136/bmjopen-2012-001529

[12] Tewodros Alemayehu, Jemal Haidar, Dereje Habte. Determinants of exclusive breastfeeding practices in Ethiopia. Ethiop.J.Health Dev. 2009; 23(1):12-18]

[13] Kok Leong Tan. Factors associated with exclusive breastfeeding among infants under six months of age in peninsular Malaysia. International Breastfeeding Journal, BMC, 2011; 6:2 http:// www. internationalbreastfeedingjournal.com/content/6/1/2

[14] Upul Senarath, Michael J. Dibley, S. S. P. Godakandage etal. Determinants of infant and young child feeding practices in Sri Lanka: Secondary data analysis of Demographic and Health Survey 2000. Food and Nutrition Bulletin, 2010, vol. 31 , no. 2

[15] Haque M J, Rahman MM, Sarker SK, Ali MA, Fakir M, Rahman MM, Islam MM). Infant Feeding Practice by Rural Mothers of Dinajpur District, Bangladesh. Dinajpur Med Col J. 2010; 3 (1):35-38
[16] R. N. O. Aryeetey and y. E. Goh, duration of exclusive breastfeeding and subsequent child feeding adequacy in Ghana, Ghana Medical Journal, 2013 Vol 47 No1.

[17] Madan Mohan Laddunuri, Patterns and Determinants of Breast Feeding Practices in Dodoma Municipality Tanzania. Journal of Food Studies, 2012, Vol. 1, No. 1). doi:10.5296/jfs.v1i1.1566: http: //dx. doi.org / 10.5296/jfs.v1i1.1566

[18] Henry Wamani, Anne Nordrehaug A strøm, Stefan Peterson, Thorkild Tylleska, and James K. Tumwine. Infant and Young Child Feeding in Western Uganda: Knowledge, Practices and Socio-economic Correlates, Journal of Tropical Pediatrics. 2005, Vol. 51, No. 6

[19] Tesfaye Setegn, Tefera Belachew, Mulusew Gerbaba, et al. Factors associated with EBF practices among mothers in Goba district, Southeast Ethiopia. International Breastfeeding Journal 2012, 7:17 http:// www. internationalbreastfeedingjournal.com/content/7/1/17)

[20] Dat V Duong, Andy H Lee, Colin W Binns. Determinants of breast-feeding within the first 6 months post-partum in rural Vietnam, Journal of Paediatrics and Child Health, 2005. Vol 41, Issue7 pp 338-343, DOI: $10.1111 / \mathrm{j} .1440-1754.2005 .00627 . \mathrm{x}$

[21] Ludvigsson, J. F. and Ludvigsson, J. Socio-economic determinants, maternal smoking and coffee consumption, and exclusive breastfeeding in 10205 children Sweden. Acta Paediatrica, Nurturing the child. Sept 2005, Vol 94: Issue 9; pp 1310-1319,. DOI: 10.1111/j.1651-2227.2005.tb02093.x

[22] ASL Bandusena and ND Warnasuriya: Selected determinants and squeal of exclusive breastfeeding up to six months among infants attending chosen well baby clinics in the Colombo District Sir Lanka. Ceylon Medical Journal. Dec 2009, Vol. 54, No. 4,: PP 124-127

[23] Al Sahab et al. Prevalence \& predictors of 6 month exclusive breastfeeding among Canadian women: a national survey. BMC Pediatrics 2010 10. http://www.biomedcentral.com/

[24] Prateek Sudhakar Bobhate, Saurabh Rambiharilal Shrivastava. Breastfeeding Practices and Factors Associated With It in India. International Journal of Public Health Research 2012, Vol 2 No 1, pp (115-121)

[25] L. L. Foo, S. J. S. Quek, S. A. NG, M. T. LIM and M. Deurenberg-YAP. Breastfeeding prevalence and practices among Singaporean Chinese, Malay and Indian mothers. Health Promotion International, Vol. 20 No. 3, doi:10.1093/heapro/dai002

[26] Mohamed M.E. Al Ghwass1 and Dalia Ahmed. Prevalence and Predictors of 6-Month Exclusive Breastfeeding in a Rural Area in Egypt. Breastfeeding medicine, Volume 6, Number 4, 201. DOI: 10.1089/bfm.2011.0035.

[27] Patil Sapna S, Hasamnis Ameya A, Pathare Rooma S, et al. Prevalence of Exclusive Breast Feeding And Its Correlates in Urban Slum, Western India; IeJSME 2009: 3 (2): pp. 14-18

[28] Kingsley E Agho, Michael J Dibley, Justice I Odiase, et al. Determinants of exclusive breastfeeding in Nigeria. BMC Pregnancy and Childbirth. 2011 http://www. internationalbreastfeedingjournal.Com / content $/ 6 / 1 / 2$ 